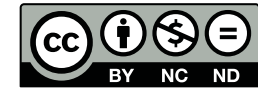

Estudos Teológicos foi licenciado com uma Licença Creative Commons Atribuição - NãoComercial - SemDerivados 3.0 Não Adaptada

http://dx.doi.org/10.22351/et.v58i1.3179

\title{
DisSERTAÇÕES E TESES: EXERCÍCIO PARA UMA IDENTIDADE DA PESQUISA SOBRE o ENSINo RELIGIOSO ${ }^{1}$
}

\author{
Dissertations and theses: exercise for a research identity \\ on Religious Education
}

\section{Sérgio Rogério Azevedo Junqueira² Claudia Regina Kluck ${ }^{3}$}

\begin{abstract}
Resumo: É por meio da pesquisa que ocorre com método e fontes confiáveis que um objeto pode ser dimensionado efetivamente, de tal forma que pesquisadores em diferentes regiões passam a ter condições de discutir os resultados desses trabalhos. Especificamente, no caso do Ensino Religioso, a pesquisa acadêmica, por meio de dissertações e teses, no cenário brasileiro é recente, um percurso aproximado de quarenta anos em campos como Educação, Ciência da Religião, Teologia, Direito, Antropologia e Sociologia. Buscando estabelecer como se deu a construção desse percurso é que o Grupo de Pesquisa Educação e Religião (GPER) estabeleceu um programa denominado Concepções e Recursos do Ensino Religioso, com o projeto Concepções e Produção Científica do Ensino Religioso, cujo objetivo é analisar o contínuo processo de construção da identidade do Ensino Religioso como componente curricular a partir da produção científica sobre esse tema. Este artigo é resultado de tal projeto, visando estabelecer a compreensão das escolhas metodológicas realizadas para favorecer a identificação dos trabalhos sobre o objeto. Organizado em três núcleos, os pressupostos da pesquisa, o contexto e, especificamente, as dissertações e teses sobre Ensino Religioso, objetiva-se estabelecer um percurso para compreender o perfil pelo viés metodológico, ainda que seja ausente ou lacunar a sua verificação, conforme constatado pelos autores.
\end{abstract}

Palavras-chave: Educação. Ensino Religioso. Pesquisa.

1 O artigo foi recebido em 29 de novembro de 2017 e aprovado em 19 de maio de 2018 com base nas avaliações dos pareceristas ad hoc.

2 Livre docente e pós-doutor em Ciências da Religião pela Pontifícia Universidade Católica de São Paulo, pós-doutor em Geografia da Religião pela Universidade Federal do Paraná, doutor e mestre em Ciências da Educação pela Pontifícia Universidade Salesiana de Roma. Diretor do Instituto de Pesquisa e Formação Educação e Religião. Contato: srjunq@gmail.com

3 Doutoranda e mestra em Teologia pela Pontifícia Universidade Católica do Paraná, Graduação em Pedagogia com especialização em Gestão Escolar (UCB) e licenciatura em História (UNOPAR), membro do Grupo de Pesquisa Educação e Religião. Pesquisadora Sênior do Instituto de Pesquisa e Formação Educação e Religião - IPFER. Contato: claudiakluck@gmail.com 
Abstract: It is through the research that occurs with method and reliable sources that an object can be dimensioned effectively, in such a way that researchers in different regions are able to discuss the results of these works. Specifically, in the case of Religious Education, the academic research through dissertations and theses in the Brazilian scenario is recent, an approximate course of forty years in fields such as education, Religious Studies, theology, law, anthropology and sociology. Seeking to establish how this course was built, the Education and Religion Research Group (GPER) has established a program called Conceptions and Resources of Religious Education, with the project Conceptions and Scientific Production of Religious Education, whose objective is to analyze the continuous process of construction of the identity of Religious Education, as a curricular component, from the scientific production on this theme. This article is the result of such a project, aiming to establish the understanding of the methodological choices made to favor the identification of the works on the object. Organized in three nuclei, the research presuppositions, the context and, specifically, the dissertations and theses on Religious Teaching, aims to establish a course to understand the profile, by the methodological bias, even if its verification is absent or incomplete, according to verified by the authors.

Keywords: Education. Religious Education. Research.

\section{Pressupostos da pesquisa}

Este artigo é o resultado da pesquisa do Programa Concepções e Recursos do Ensino Religioso no projeto Concepções e Produção Científica do Ensino Religioso e tem o objetivo de analisar o contínuo processo de construção da identidade do Ensino Religioso (ER) como componente curricular, a partir da produção científica realizada sobre esse componente curricular. É uma pesquisa qualitativa, descritiva e documen$\mathrm{tal}^{4}$, compreendendo que documento é qualquer suporte que contenha informação registrada, formando uma unidade, que possa servir para consulta, estudo ou prova. ${ }^{5}$ Incluem-se nesse universo os impressos, os manuscritos, os registros audiovisuais e sonoros, as imagens, entre outros. ${ }^{6}$

A focalização desta pesquisa é a compreensão das escolhas metodológicas cuja assunção pode permitir identificar trabalhos a respeito daquelas centradas no ER, tendo em vista que essa identificação, a respeito das escolhas teórico-metodológicas específicas do campo investigado, contribui aditivamente validando-as e possibilitando ampliar as contribuições encontradas.

A pesquisa acadêmica indica a necessidade de se ter clareza a respeito do objeto, das fontes, além da metodologia que a guiará, a fim de que se possa planejar o percurso, como um viajante que estuda o caminho e se municia de condições para chegar ao final da jornada. Não obstante, há que se conservar em mente que a pesquisa

4 GIL, C. Como elaborar projetos de pesquisa. 4. ed. São Paulo: Atlas, 2002.

5 ASSOCIAÇÃO BRASILEIRA DE NORMAS TÉCNICAS - ABNT. NBR 6023:2002 ABNT/CB-14. Rio de Janeiro, 2002.

6 APPOLINÁRIO, F. Dicionário de metodologia científica: um guia para a produção do conhecimento científico. São Paulo: Atlas, 2009. p. 67. 
é norteada por uma teoria que a embasa e com procedimentos específicos (métodos e técnicas de coleta e análises de dados) que estão intimamente ligados entre si e que indicam sempre escolhas realizadas pelo pesquisador para abordar o objeto. Assim, teoria e método são termos interdependentes e inseparáveis. Entende-se que uma das formas de verificação a respeito da maturação de uma área de pesquisa é a reflexão quanto às produções acadêmicas dos programas de pós-graduação strictu sensu (mestrado/doutorado). A importância dessa etapa formativa se indica desde a década de 1960, cujo parecer CESU-977/65 orientava sua implantação no sistema brasileiro, aferindo valor a esses estudos que, específicos e especializados, implementaram a formação avançada e a pesquisa científica.

Seu objetivo imediato é, sem dúvida, proporcionar ao estudante o aprofundamento do saber de tal forma que seja possível alcançar elevado padrão de competência profissional, que teria sido limitado na graduação. Outra possibilidade com a pós-graduação é desenvolver na universidade o potencial de pesquisa, considerando o rigor científico que a investigação exige no ambiente universitário. A pós-graduação pauta-se em três orientações basilares: a formação docente que dê conta do atendimento da expansão quantitativa do ensino superior; ampliação da qualidade no atendimento a esse nível de ensino e desenvolvimento da pesquisa científica, fornecendo condições para a formação de pesquisadores, docentes ou não, que recebam treinamento para atuar com qualidade no desenvolvimento de pesquisas.

É responsabilidade dos pesquisadores a validação dos resultados de suas pesquisas de forma que alcancem credibilidade. Na medida em que são publicadas, submetidas às discussões de outros pesquisadores, em periódicos, em comitês e em congressos, que, criticamente, as enriquecem, confirma-se o pensamento de Adami e Marchiori”, para quem "entende-se que a vaidade de um conhecimento científico está atrelada à sua submissão à comunidade científica".

Assim como outras disciplinas escolares, as pesquisas a respeito do componente curricular ER têm suscitado trabalhos e contribuições da comunidade acadêmica.

É possível observar o desenvolvimento das mesmas refletindo a respeito dos ensaios construídos, entendendo como ensaio a exposição lógica e reflexiva, em argumentação rigorosa com um nível de interpretação e julgamento do autor. ${ }^{8}$

Já na década de 1930 há registros dos primeiros materiais teóricos que subsidiariam a discussão a respeito da inclusão do ER no currículo oficial brasileiro. É ele o publicado por Leonel Franca em 1931, sob o título "Ensino Religioso e Ensino Leigo: aspectos pedagógicos, sociais e jurídicos”, na cidade do Rio de Janeiro pela Schmidt Editora. Outro material é o de P. Werner, em 1933, publicado pela Livraria Globo, em Porto Alegre, denominado "Os problemas nacionais e o Ensino Religioso".

Com relação a artigos em periódicos, foram localizados na Revista Eclesiástica Brasileira, em 1941, por Paul Tochwic, o título “O que se pretende com a instrução

7 ADAMI, A.; MARCHIORI, P. Autoria e leitura de artigos por docentes pesquisadores: motivações e barreiras. In: FERREIRA, S.; TARGINO, M. (Orgs.). Preparação de revistas cientificas: teoria e prática. São Paulo: Reichmann, 2005. p. 73.

8 SEVERINO, A. Metodologia do trabalho cientifico. 21. ed. rev. e ampl. São Paulo: Cortez, 2000. p. 72. 
religiosa". Em 1942, Álvaro Negromonte publicou sobre "O catecismo nas escolas"; e Valdomiro Pires Martins, "O ensino do catecismo nos Colégios Religiosos", em 1947.

Não obstante o início das discussões sobre a temática nas décadas de 1930 e 1940, só nos anos 1970 se tem a primeira dissertação. De autoria de Romeu Gomes, em 1975, foi defendida na Universidade Federal Fluminense, com o título "A não diretividade na Educação Religiosa: estudo de caso com adolescentes", no Programa de Educação. Somente 25 anos depois, em 2000, foi encontrada uma tese, considerada precursora, no programa de Teologia da Pontifícia Universidade Católica do Rio de Janeiro, da autoria da professora Carmencita de Araújo Sefrim. Essas informações são elas próprias resultados de pesquisas que buscaram o estado da arte, realizadas por pesquisadores brasileiros, e que contribuíram para entender a produção a respeito da disciplina no cenário brasileiro.

Com relação aos trabalhos acadêmicos voltados ao ER, é possível aferir que já em 2003 o Grupo de Pesquisa Educação e Religião contribuiu para o entendimento a respeito dessa área por meio de um mapeamento da pesquisa científica.

$\mathrm{Na}$ fase inicial, uma das dificuldades percebidas no levantamento do corpus da pesquisa, foi a busca pela produção científica no site do CNPq, em que se verificou dificuldade de acesso à Plataforma Lattes. Além disso, houve certa mudança no elenco de referências de pesquisadores e autores que tornaram morosa a pesquisa. Isso em si mesmo depõe a respeito da área pesquisada, revelando a necessidade de atualização dos autores e em outra instância tornando possível conjecturar a respeito das condições das fontes das pesquisas e das metodologias empregadas nas mesmas, cuja dinamicidade deve buscar a profissionalização junto à comunidade acadêmica.

Ao lançar um olhar minucioso sobre os materiais levantados, descortina-se em primeiro plano que eles versam a respeito (1) da importância do ER escolar, (2) da preocupação com a formação docente para atuar no ensino básico e (3) de reflexões a respeito de propostas curriculares para a disciplina. Outro dado bastante encontrado é a descrição do caminho histórico tomado pelo ER, assim como a indicação da interdisciplinaridade, apontada como necessária ao melhor fazer em sala de aula. Aparecem também, porém, com menor incidência, a cidadania e sua construção como enfoque da disciplina, questões de gênero e a preocupação com relação à convivência na diversidade religiosa brasileira, traduzida por vezes pelo termo "ecumenismo".

Entre 2005 a 2007, um segundo mapeamento foi realizado pela Prof. ${ }^{a}$ Dra. Lurdes Caron para a sua tese de doutorado. Um terceiro trabalho ocorreu entre o segundo semestre de 2008 e primeiro de 2009, pelo Grupo de Pesquisa Religião e Educação do Programa de Pós-Graduação de Ciências da Religião da PUCSP, em que se constatou a existência de 50 teses e dissertações relativas ao ER.

Em 2016, em busca de revisar e atualizar o projeto de mapeamento da produção, buscou-se especificamente sondar dados identitários dos materiais no que concerte ao ER, sendo possível destacar a metodologia escolhida e apresentada por dissertações e teses.

Efetivamente, percebe-se um crescimento exponencial de informações por conta da especialização dos pesquisadores em diversas áreas do conhecimento e, como consequência, a multiplicação de textos sobre a temática que exigem uma clas- 
sificação e categorização dessas produções. À medida que cresce o número de objetos de informação, quer seja quantitativo ou qualitativo esse crescimento, é preciso aumentar o número de índices e cuidar para que esses lhes agreguem algum valor. Outra preocupação refere-se ao gigantismo dos próprios índices, como acontece, por exemplo, com as bases de dados criadas pelos mecanismos de busca na internet e os catálogos das maiores bibliotecas. Nesse cenário informacional, as revisões de literatura, principalmente, por seu aspecto sumarizador, assumem importante função orgânica juntamente com os índices, abstracts e as bibliografias especializadas. Verifica-se que o ER é objeto de pesquisa em diferentes campos do conhecimento como Educação, Teologia, Ciência da Religião, Filosofia, Direito, Sociologia, Antropologia, Psicologia e outros. Encontramos publicações em periódicos, anais, livros, com destaque para dissertações e teses. Especialmente nestas últimas, percebe-se que atuam tangencialmente ou diretamente sobre esse tema. Antes de discutir a produção identificada sobre o ER, é importante compreender o conhecimento. Para tal consideramos que o ser humano desde o início de sua existência se depara com um mundo que lhe é totalmente desconhecido, o qual precisa ser descoberto. Nessa relação entre sujeito e objeto começa a compreender e a representar a si e ao mundo que o cerca passando a dar forma e significado a estes e, assim, conhecê-los. ${ }^{9}$

Neste contexto está a discussão sobre o ER, que compreende a religião também como um tipo de conhecimento humano, efetivamente, compreendendo o fenômeno religioso como uma leitura das manifestações culturais na sociedade que considera o estudo da religião na cultura em geral. "Atualmente, considera-se como marco referencial a concepção de que o fenômeno religioso se manifesta em uma cultura. É a cultura que marca profundamente a maneira de ser e viver do ser humano." ${ }^{10}$ Em todas as culturas existentes, encontramos um traço sempre marcante, a presença da religião; estudar esse fato é não somente necessário, como indispensável. Dessa forma, o ER tem por ação sensibilizar os alunos para a necessidade de valorizar a experiência religiosa própria e a dos outros. Para tanto, existe esse espaço concreto que é o da sala de aula. É nesse contexto que se dá também a construção acadêmica do saber religioso. O ER é um saber que se constrói. Nas palavras de Oliveira ${ }^{11}$, como área do conhecimento, o ER constrói significados com base nas relações que os alunos estabelecem no entendimento da sua experiência religiosa. Essas construções vão arquitetando-se pelos diferentes processos de observação que se constata, pela reflexão acerca do que se observa e pela informação sobre o que se reflete de forma continuada.

O que está exigindo que em cada tipo de conhecimento exista um objeto e um método de produção para realizá-lo, bem como a diferença entre o conhecimento do senso comum e o conhecimento científico. Pois o conhecimento do senso comum é o conhecimento acumulado pelos seres humanos, de forma empírica, baseado apenas na experiência cotidiana, sem se preocupar com o rigor da experiência científica. A produ-

9 JUNQUEIRA, S. et al. Socialização do saber e produção científica do Ensino Religioso. Porto Alegre: FI, 2017. p. 21-28.

${ }^{10}$ OLIVEIRA, E. Fundamentos Epistemológicos do Ensino Religioso. Curitiba: Ibpex, 2009. p. 67.

11 OLIVEIRA, 2009, p. 115. 
ção do conhecimento científico inicia com o reconhecimento de uma situação problema, sobre a qual o pesquisador formula possíveis hipóteses e propõe a busca da causa ou solução dessa situação. A partir dessas situações postas, utiliza-se a força de um espírito investigativo; metodicamente verificam-se cada uma delas para, finalmente, com a confirmação de alguma hipótese ou questão, produzir-se um novo conhecimento.

Mas, apesar de todo esse esforço metódico para produzir-se conhecimento, é preciso ter em mente que a ciência é passível de falhas, existindo assim a possibilidade do conhecimento ser refutado. A realidade do conhecimento científico só é estabelecida após sua comprovação ser efetivada, demonstrada e experimentada. "O conhecimento científico é extremamente importante para a sociedade, pois é a partir dele que é possível a transformação social e tecnológica."12

O conhecimento científico, segundo Lakatos e Marconi ${ }^{13}$, possui as seguintes características: (1) real: porque lida com ocorrências ou fatos; (2) contingente: suas proposições ou hipóteses têm veracidade ou falsidade conhecida através da experiência e não apenas pela razão; (3) sistemático: trata de um saber ordenado logicamente, formando um sistema de ideias conexas; (4) verticalidade: os resultados devem estar explícitos, devem ser comprovados; (5) falível: não é absoluto, definitivo; (6) aproximadamente exato: novas proposições e pesquisas podem gerar resultados diferentes, reformulando assim o acervo existente.

Portanto o ER, enquanto disciplina, enquadra-se no padrão comum a todas as outras áreas do conhecimento, ou seja, tem: objeto de estudo: o fenômeno religioso; conteúdo próprio: conhecimento religioso; tratamento didático: didática do fenômeno religioso; objetivos definidos; metodologia própria; sistema de avaliação; inserção no sistema de ensino. Esse componente curricular, por meio do seu conhecimento específico e, articulando religião e cultura, tem como desafio, diante da incerteza, da contradição, da descontinuidade dos fatos, da quebra dos valores e das normas sociais que vivemos na sociedade contemporânea, contribuir na reconstrução das utopias e dos horizontes dos seres humanos. Outra meta a alcançar é a de incentivar a vivência e a descoberta de valores fundamentados na ética; de favorecer relações interpessoais fraternas, solidárias e justas; bem como desenvolver a consciência planetária, resgatar a essência do ser humano, para que juntos possamos construir um mundo melhor.

\section{Dissertações e teses: percurso para compreender o perfil metodológico}

$\mathrm{O}$ recorte temporal desta pesquisa foi entre o ano de localização da primeira dissertação (1975) e da primeira tese (2000) até 2015. O que significam 206 trabalhos de mestrado e 33 de doutorado. Assim distribuídos ao longo desses quarenta anos:

\footnotetext{
${ }^{12}$ GARCIA, A. M. F. O Conhecimento. In: HÜHNE, Leda Miranda (Org.). Metodologia cientifica: caderno de textos e técnicas. 7. ed. Rio de Janeiro: Agir, 1997. p. 45.

13 LAKATOS; MARCONI, 2003, p. 80.
} 


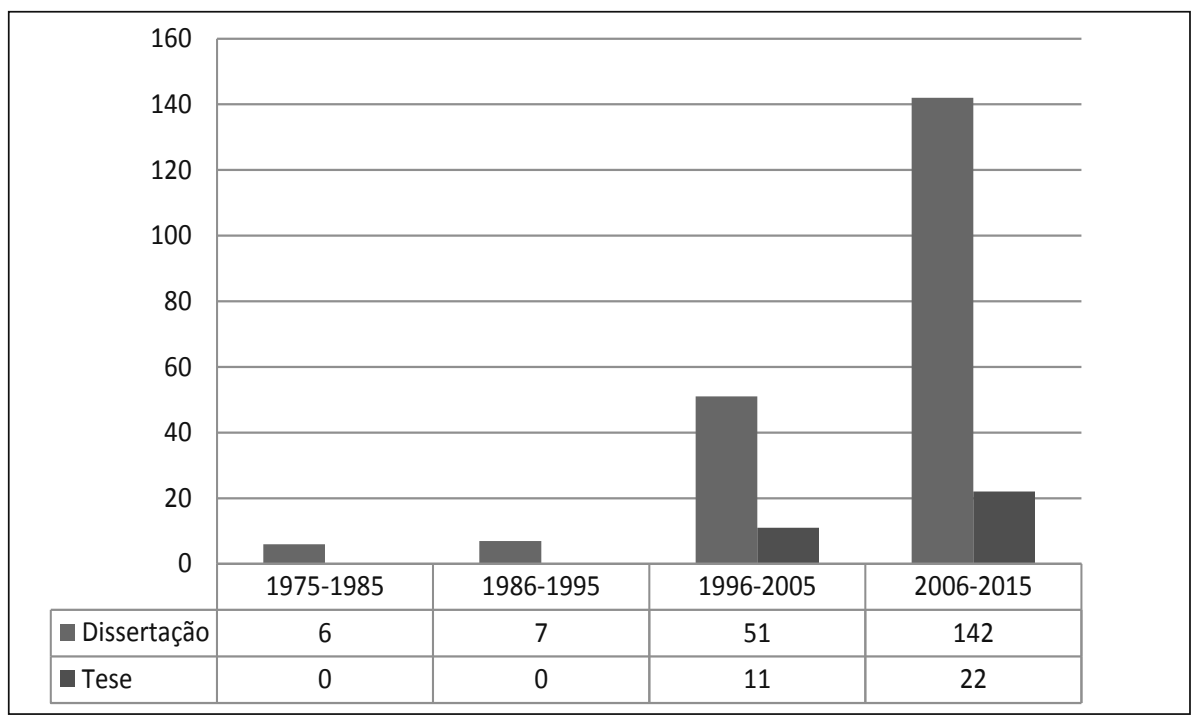

Gráfico 01 - Distribuição cronológica de dissertações e teses Autor: JUNQUEIRA

Percebe-se um período especialmente profícuo a partir do ano de 1996, com a promulgação da Lei de Diretrizes e Bases da Educação, em especial, com a revisão do artigo 33 (lei 9475), em 1997, cujo interesse foi ampliado sobremaneira. Isso também se confirma no período entre 2006 e 2015, com uma proporção relevante de dissertações e teses ${ }^{14}$, conforme demonstrado no gráfico acima.

Refletindo sobre os dados encontrados, é possível aferir que entre mestres e doutores, a proporção desses últimos é de menos de $20 \%$ do total de trabalhos de pós-graduação, o que indica a situação incipiente no que tange a trabalhos de doutorado sobre o ER. Além disso, os dados revelados por meio do gráfico 02 abaixo apresentam que o número de doutores representa $5 \%$ do total de autores que defenderam seus trabalhos, confirmando a afirmação anterior a respeito das pesquisas para a área.

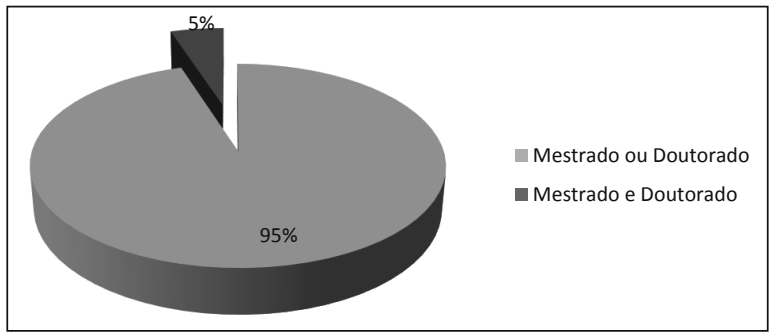

Gráfico 02 - Distribuição dos autores de dissertações e teses Autor: JUNQUEIRA

${ }^{14}$ Cf. JUNQUEIRA et al., 2018, p. 188-190. 
O levantamento de dados revela, ainda, que a proporcionalidade entre homens e mulheres, entre aqueles que publicaram dissertações, com uma leve superioridade nas publicações de autoras, conforme Gráfico 03. Ainda assim, é possível constatar que há interesse tanto de pesquisadoras como de pesquisadores na temática.

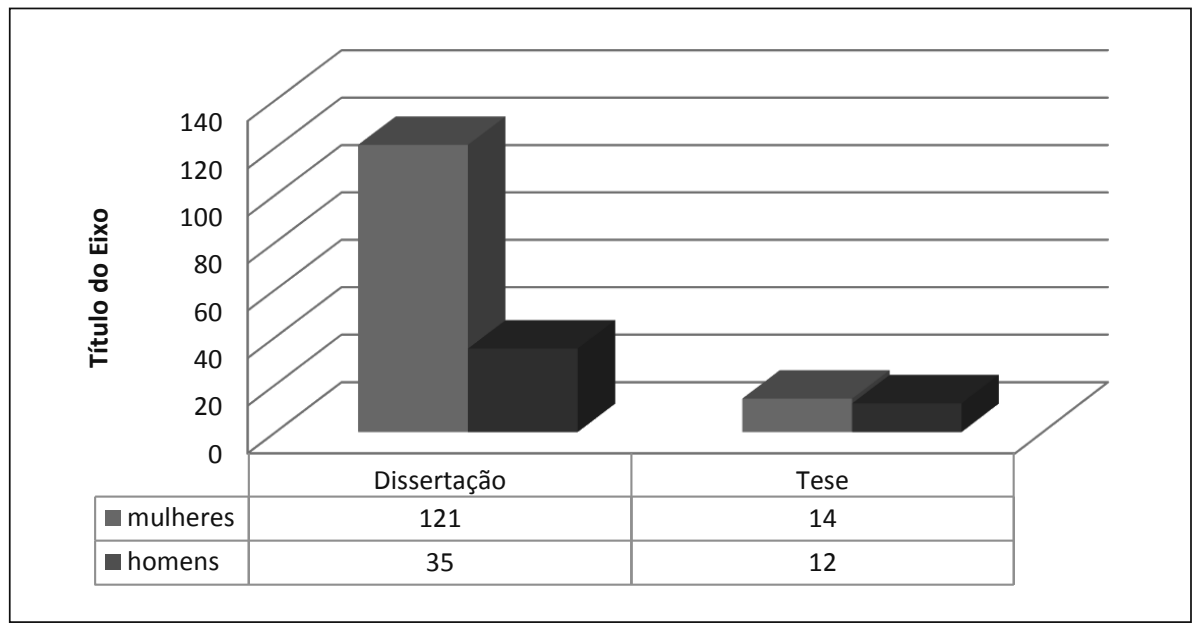

Gráfico 03 - Distribuição de gênero dos/as autores/as de dissertações e teses Autor: JUNQUEIRA

Diferentes áreas e programas têm se debruçado na pesquisa e reflexão a respeito do ER como, por exemplo, Direito, Sociologia e Antropologia, Psicologia, Políticas Sociais, Linguística e Língua Portuguesa e, prioritariamente, na Educação, Ciências da Religião e Teologia, conforme gráfico abaixo.

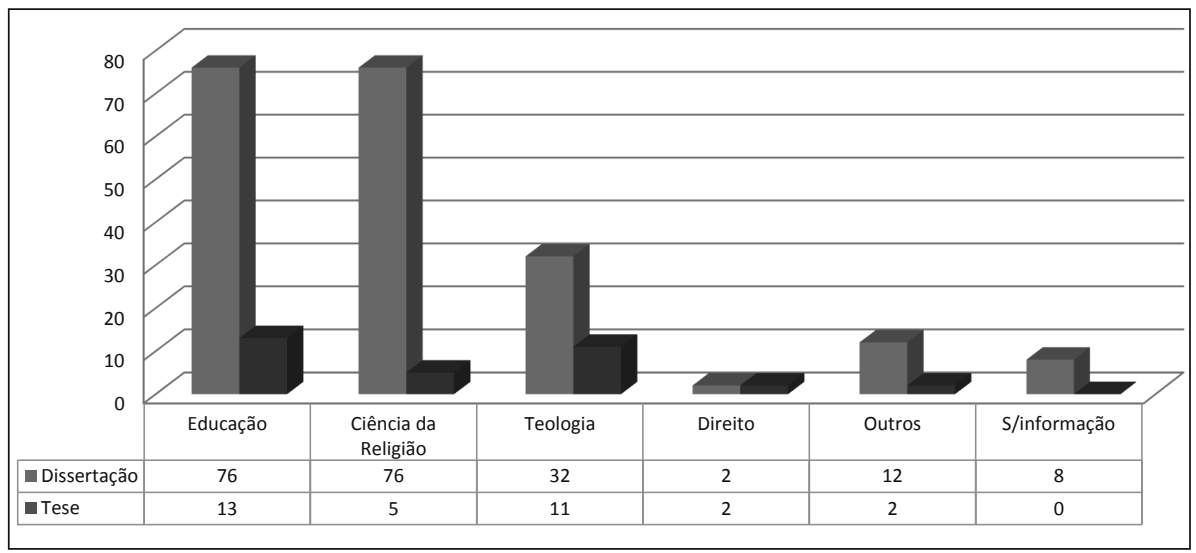

Gráfico 04 - Distribuição dos programas

Autor: JUNQUEIRA 
A materialidade da pesquisa revelou que as instituições confessionais promoveram maior número de defesas tanto de mestrado como de doutorado, contudo existe produção de pesquisa no âmbito de instituições de ensino superior públicas.

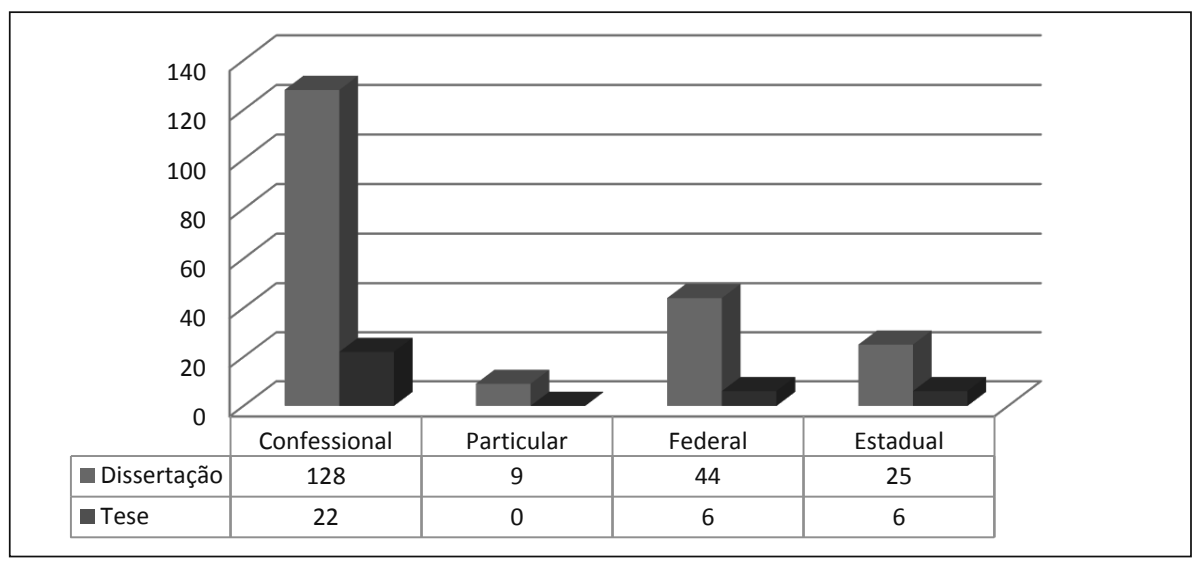

Gráfico 05 - Distribuição da tipologia das instituições de ensino superior Autor: JUNQUEIRA

Geograficamente, as regiões Sul e Sudeste têm relevância na produção acadêmica para a temática, sendo possível aferir que programas de pós-graduação dessas regiões têm impacto na produção a respeito do ER, conforme demonstrado no gráfico a seguir.

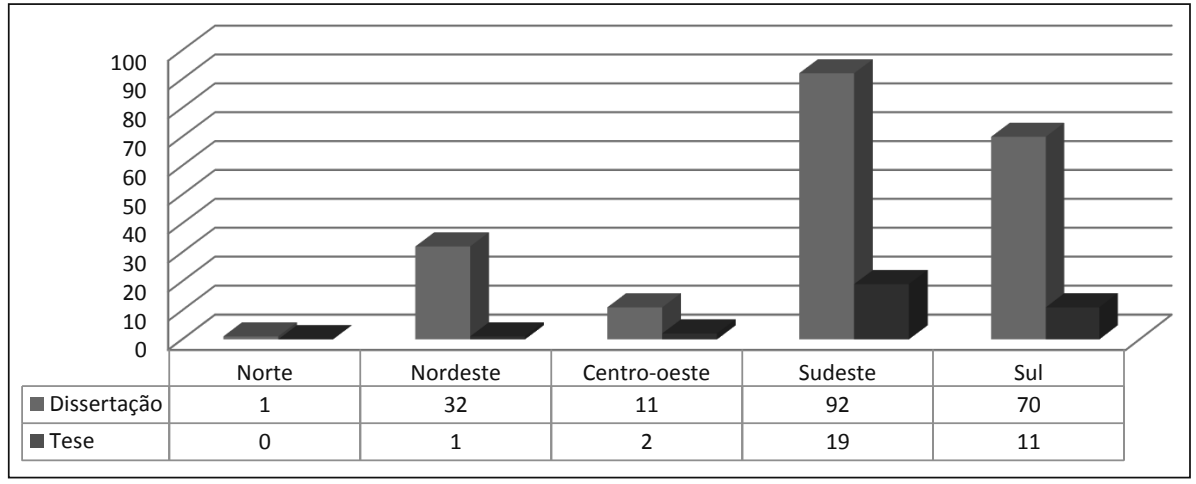

Gráfico 06 - Distribuição da produção por regiões geográficas Autor: JUNQUEIRA

\section{Entendendo a pesquisa científica}

Pesquisar cientificamente é procedimento que requer método e tem por objetivos conhecer, interpretar e intervir na realidade, dentre outros. A partir de uma 
problematização, sustentam-se diretivas que pretendem compor e constituir um conhecimento sistematicamente construído.

É previsto que o/a pesquisador/pesquisadora que pretende atuar em programas de pós-graduação, seja formado/formada por meio de programas de mestrado e doutorado e que produza, respectivamente, uma dissertação e uma tese.

Essa pode servir-se de caminhos que a qualificam como sendo pesquisa de campo, documental, de campo, histórica, experimental ou filosófica. E que deve contribuir ao solucionar uma problemática, embasada em corpo teórico e que deve demonstrar evidências de suas hipóteses de forma lógica e racional, contribuindo para o avanço da pesquisa acadêmica em cada área.

No caso da primeira, a dissertação, o/a pesquisador/pesquisadora reage ou compõe sobre determinado tema, constituindo argumentos, modos de ver, explicações, que o constituirão a fim de desenvolver análise e interpretação cada vez mais minuciosa. A dissertação exige, portanto, conhecer, amadurecer e discutir um tema de maneira que argumento e lógica deem conta de exprimir conclusões, de maneira apropriada e que possam remeter a aprofundamentos. Em geral, essa escrita inclui uma introdução, o desenvolvimento dos argumentos e teorias e, finalmente, uma porção específica para apresentação de suas conclusões. Essa pesquisa inicial, consoante com a área de concentração e programa na qual está abrigada, também tem relação direta com a pesquisa $\mathrm{do} / \mathrm{da}$ orientador/orientadora enquanto pesquisador/pesquisadora mais experiente. Por isso é possível entender a dissertação como um relatório de pesquisa no qual são expressos objetos e fontes claras e fundamentadas, contribuindo para a delimitação e o diálogo do objeto com o tema problematizado resultante de uma interação. ${ }^{15}$

No doutorado, a tese propõe-se a desenvolver um raciocínio com base em proposições baseadas em hipóteses ou pressupostos que se confirmam ou se refutam com o desenvolvimento da pesquisa. O resultado da pesquisa será defendido publicamente para validar-se e vir a constituir um corpo de conhecimento.

Espera-se que a tese de doutorado seja original e que apresente relevância contribuindo para o desenvolvimento humano, quer seja científico, tecnológico, cultural ou outro, valorizando a inovação e apontando caminhos, processos e patentes inéditas.

Em ambos os casos está envolvida a necessidade de uma metodologia, enquanto ferramenta de análise que dê conta de discernir o objeto da pesquisa e sua teoria, de forma inter-relacionada, que sejam aptas às fundamentais conceitos e desdobramentos da temática. É possível aferir, contudo, que inexiste uma metodologia definitiva, sendo variável ao objeto e ao questionamento ou problematização proposta. Assim diferentes instrumentos se prestam a responder uma variação de temas e indagações a seu respeito, e não se mostram aptos a outros questionamentos. Ou seja, é variável a eficácia de alguns meios de levantamento de dados, dependentes, por exemplo, do marco teórico que se utiliza. Assim, a metodologia de pesquisa deve se adequar ao tipo de resposta que se busca que podem ser confirmadas ou desmentidas pelo tratamento oferecido ao tema escolhido.

${ }^{15}$ Cf. JUNQUEIRA et al., 2018, p. 188-190. 
São de especial importância os métodos revelados pelas dissertações e teses encontradas, conforme demonstrado pelo quadro abaixo.

\begin{tabular}{|c|c|c|}
\hline Temas & Mestrado - Dissertação & Doutorado - Tese \\
\hline $\begin{array}{l}\text { Abordagens e modelos / } \\
\text { Metodologia }\end{array}$ & $\begin{array}{l}\text { A identidade da disciplina } \\
\text { Relação com a cultura } \\
\text { Diretrizes pedagógicas } \\
\text { Diversidade religiosa } \\
\text { Modelos do Ensino } \\
\text { Religioso } \\
\text { Leitura pedagógica do } \\
\text { Ensino Religioso }\end{array}$ & $\begin{array}{l}\text { Pensamento pós-moderno } \\
\text { Concepção pedagógica } \\
\text { Identidade religiosa } \\
\text { Fundamentos culturais } \\
\text { Espaço escolar } \\
\text { Aprender e ensinar } \\
\text { Papel das Ciências da } \\
\text { Religião } \\
\text { Ensino inter-religioso } \\
\text { Aportes epistemológicos } \\
\text { Educar por competência }\end{array}$ \\
\hline Conteúdo & $\begin{array}{l}\text { Fenômeno religioso } \\
\text { Matrizes africanas } \\
\text { Pluralismo religioso } \\
\text { Eixos do parâmetro } \\
\text { curricular }\end{array}$ & Sem identificação \\
\hline Estratégias e recursos & $\begin{array}{l}\text { Roteiro cultural } \\
\text { Audiovisuais } \\
\text { Brincadeiras de roda entre } \\
\text { crianças } \\
\text { Literatura } \\
\text { Livro didático }\end{array}$ & $\begin{array}{l}\text { Jogos } \\
\text { Didática magna }\end{array}$ \\
\hline Diversos & $\begin{array}{l}\text { Valores éticos e morais } \\
\text { Via de humanização } \\
\text { Laicidade }\end{array}$ & $\begin{array}{l}\text { Educação nos terreiros } \\
\text { Étnico-racial }\end{array}$ \\
\hline Faixa etária / Gênero & $\begin{array}{l}\text { Adolescência } \\
\text { Criança } \\
\text { Desenvolvimento da fé }\end{array}$ & Sem identificação \\
\hline $\begin{array}{l}\text { Personagem / História / } \\
\text { Legislação }\end{array}$ & $\begin{array}{l}\text { Contribuição da Igreja } \\
\text { Católica Apostólica Romana } \\
\text { James William Fowler } \\
\text { Legislação e aplicabilidade } \\
\text { Lei de Diretrizes e Bases da } \\
\text { Educação Nacional } \\
\text { Leonel Franca } \\
\text { Monsenhor Alonso } \\
\text { Pareceres de Rui Barbosa } \\
\text { (1882-1883) } \\
\text { Políticas públicas } \\
\text { Wolfgang Gruen }\end{array}$ & $\begin{array}{l}\text { Legislação e } \\
\text { institucionalidade } \\
\text { Liberdade religiosa } \\
\text { Interpretação } \\
\text { Laicidade } \\
\text { Álvaro Negromonte } \\
\text { História do Ensino Religioso }\end{array}$ \\
\hline
\end{tabular}




\begin{tabular}{|c|c|c|c|c|}
\hline \multicolumn{2}{|r|}{$\begin{array}{ll}1 \\
1 \\
1 \\
1 \\
1 \\
1 \\
1 \\
1 \\
\\
1 \\
1 \\
1 \\
1 \\
1 \\
1 \\
1 \\
1\end{array}$} & $\begin{array}{l}\text { Análise de modelos de } \\
\text { Ensino Religioso e de } \\
\text { práticas docentes } \\
\text { Análise semiótica do } \\
\text { discurso da formação } \\
\text { Cursos de pós-graduação } \\
\text { lato sensu } \\
\text { Desafios à prática docente } \\
\text { Desenvolvimento da fé em } \\
\text { professores } \\
\text { História, formação e perfil } \\
\text { do docente da rede pública } \\
\text { estadual } \\
\text { História, formação e perfil } \\
\text { do docente da rede pública } \\
\text { estadual } \\
\text { Pedagogia e projetos face à } \\
\text { pluralidade cultural } \\
\text { Práxis do Ensino Religioso } \\
\text { na escola }\end{array}$ & \multicolumn{2}{|c|}{$\begin{array}{l}\text { Formação de professor } \\
\text { Impacto virtual } \\
\text { Práticas curriculares } \\
\text { Modelos de formação } \\
\text { Jornadas de formação }\end{array}$} \\
\hline $\begin{array}{l}\text { Região } \\
\text { geográfica }\end{array}$ & $\begin{array}{l}\text { Amapá } \\
\text { João Pessoa } \\
\text { Paraná } \\
\text { Rio de Janeiro } \\
\text { São Paulo }\end{array}$ & \begin{tabular}{l|l} 
Anápolis \\
Aparecida de Goiânia \\
Assis \\
Belo Horizonte \\
Boa Vista \\
Cariacica \\
Colatina \\
Curitiba \\
Florianópolis \\
Goiânia \\
Juazeiro do Norte \\
Juiz de Fora \\
Mariana \\
Mirinzal \\
Montes Claros \\
Ouro Preto \\
Porto Alegre \\
Porto Velho \\
Presidente Prudente \\
Recife \\
Sabará \\
Salgado de São Feliz \\
Salvador \\
Santos \\
São Paulo \\
Teresina \\
Vitória
\end{tabular} & $\begin{array}{l}\text { Santa Catarina } \\
\text { Rio de Janeiro }\end{array}$ & Florianópolis \\
\hline
\end{tabular}




\begin{tabular}{|l|l|l|}
\hline Segmento & $\begin{array}{l}\text { Ensino fundamental } \\
\text { Ensino médio } \\
\text { Pré-escola }\end{array}$ & Anos iniciais \\
\hline $\begin{array}{l}\text { Tipologia de } \\
\text { escola }\end{array}$ & $\begin{array}{l}\text { Acordo Brasil - Santa Sé } \\
\text { Associação Franciscana de Ensino } \\
\text { Senhor Bom Jesus } \\
\text { Colégio Progresso Campineiro } \\
\text { Colégios protestantes em Pernambuco } \\
\text { Companhia de Jesus - A proposta } \\
\text { inaciana expressa nos documentos da } \\
\text { província do Brasil Centro - Leste } \\
\text { Educação católica } \\
\text { Ensino Religioso protestante } \\
\text { Companhia de Jesus } \\
\text { Mística inaciana } \\
\text { Comparativo de escolas } \\
\text { Escola pública } \\
\text { Província Marista Brasil Centro-Norte } \\
\text { Rede educacional adventista } \\
\text { Rede pública estadual }\end{array}$ \\
\hline $\begin{array}{l}\text { Artigos } \\
\text { Eventos } \\
\text { científica }\end{array}$ & $\begin{array}{l}\text { Livros } \\
\text { Teses e dissertações }\end{array}$ & \\
\hline
\end{tabular}

Tabela 01 - Temas de dissertações e teses Autor: JUNQUEIRA

Essencialmente, os temas discutiram a questão histórica dos personagens que organizaram essa memória, a estrutura do processo escolar como os segmentos escolares, metodologia, conteúdo e abordagens. Esses conteúdos permitiram estabelecer o cenário e a estrutura do componente curricular. Esses foram desenvolvidos a partir de métodos que é o processo para se atingir um determinado fim ou para se chegar ao conhecimento. Após o estudo dos 239 trabalhos acadêmicos (teses e dissertações), verificamos que a indicação e descrição do método não é algo presente nas dissertações e teses.

Quanto à abordagem, registrou-se que $85 \%$ dos que identificaram a tipologia como qualitativa quanto aos objetivos assumem um perfil descritivo e explicativo, sendo as informações obtidas sem a preocupação de quantificar. Os autores indicam que os procedimentos utilizados são os da pesquisa bibliográfica, documental, histórica e narrativa. E ainda há ocorrência de pesquisa de campo, etnográfica, estado da arte, estudo de caso e grupo focal.

Observando os dados apresentados na tabela anterior, é perceptível que a construção dos saberes busca tratar sobre o pluralismo religioso, os valores éticos e morais, e a laicidade, temas que se mostram lastros essenciais para as aulas de ER. Também estão presentes assuntos que indicam o atendimento da Lei $\mathrm{n}^{\circ} 10.639$, que incluiu a 
obrigatoriedade da temática "História e Cultura Afro-Brasileira"16, com os seguintes temas: matrizes africanas, educação nos terreiros e étnico-racial.

\section{Considerações finais}

A pesquisa acadêmica sobre o ER busca utilizar métodos que visam à objetividade na perspectiva de identificar a história, a compreensão do processo de ensino e aprendizagem sobre a questão religiosa no espaço escolar e o impacto no cotidiano social com procedimentos que permitam verificações. Mesmo percebendo que ainda não existe uma preocupação em explicitar a metodologia em dissertações e teses sobre o Ensino Religioso, e em sua maioria são descritas como qualitativas, bibliográficas e/ou documentais. A pesquisa de campo ainda é algo em escala reduzida, efetivamente, não temos dados que demonstrem o impacto dos conteúdos, das estratégias escolhidas e, especialmente, como esse componente curricular contribui para os estudos posteriores, o mundo do trabalho e a educação integral, como proposto pela lei de educação nacional. Podemos aguardar que em décadas próximas deixemos de ter produtos como ensaios para alcançarmos, de fato, textos com objeto, fontes e método explícitos.

\section{Referências}

ADAMI, A.; MARCHIORI, P. Autoria e leitura de artigos por docentes pesquisadores: motivações e barreiras. In: FERREIRA, S.; TARGINO, M. (Orgs.). Preparação de revistas científicas: teoria e prática. São Paulo: Reichmann, 2005.

APPOLINÁRIO, F. Dicionário de metodologia científica: um guia para a produção do conhecimento científico. São Paulo: Atlas, 2009.

ASSOCIAÇÃO BRASILEIRA DE NORMAS TÉCNICAS - ABNT. NBR 6023:2002 ABNT/ CB-14. Rio de Janeiro, 2002.

BRASIL. Lei 10.639/2003, de 9 de janeiro de 2003. Altera a Lei n ${ }^{\circ}$ 9. 394, de 20 de dezembro de 1996. Diário Oficial da União, Poder Executivo, Brasília.

FRANCA, L. Ensino Religioso e Ensino Leigo: aspectos pedagógicos, sociais e jurídicos. Rio de Janeiro: Schimidt, 1931.

GARCIA, A. M. F. O Conhecimento. In: HÜHNE, Leda Miranda (Org.). Metodologia científica: caderno de textos e técnicas. 7. ed. Rio de Janeiro: Agir, 1997.

GIL, C. Como elaborar projetos de pesquisa. 4. ed. São Paulo: Atlas, 2002.

OLIVEIRA, L. et al. Ensino Religioso no ensino fundamental. São Paulo: Cortez, 2007.

JUNQUEIRA, S. et al. Socialização do saber e produção científica do Ensino Religioso. Porto Alegre: FI, 2017. p. 47-48.

MARCONI, M.; LAKATOS, E. Fundamentos de Metodologia Científica. 5. ed. São Paulo: Atlas, 2003.

MINISTÉRIO DE EDUCAÇÃO - MEC. Parecer $n^{\circ}$ 977/65, C.E.Su, aprovado em 03 de dezembro de 1965 .

${ }^{16}$ BRASIL. Lei 10.639/2003, de 9 de janeiro de 2003. Altera a Lei $n^{\circ} 9.394$, de 20 de dezembro de 1996. Diário Oficial da União, Poder Executivo, Brasília. 
OLIVEIRA, E. Fundamentos Epistemológicos do Ensino Religioso. Curitiba: Ibpex, 2009. p. 67. SEVERINO, A. Metodologia do trabalho científico. 21. ed. rev. e ampl. São Paulo: Cortez, 2000. WERNER, Pe. Os problemas nacionais e o Ensino Religioso. Porto Alegre: Globo, 1933. 